\title{
Studies on the Cold Resistance of Cassava
}

\author{
Xinglu Luo \& Qiufeng Huang \\ Agricultural College, Guanxi University, Nanning, Guangxi 530005, China \\ E-mail: luoxinglu@sina.com
}

$\begin{array}{lc}\text { Received: January 30, } 2012 & \text { Accepted: February 14, } 2012 \quad \text { Online Published: April 20, } 2012 \\ \text { doi:10.5539/jas.v4n6p104 } & \text { URL: http://dx.doi.org/10.5539/jas.v4n6p104 }\end{array}$

Sponsored project: national "973"scientific project:2010CB126601; national scientific supported project: 2008BADB8B02, 2007BAD75B02; natural scientific fund of China: 30960203; natural scientific fund of Guangxi: 2010GXNSFD013025.

\begin{abstract}
Methods: SC124 and Fuxuan 01, two cold-resistant cassava cultivars and Nanzhi199 and SC205, another two cold-sensitive cassava cultivars were studied under low temperature stress. Aims: in order to explore the hardy physiological characters of different cassava cultivars. Results: Results showed that under low temperature stress, the cell membrane permeability of the tested cassavas increased, the increase ranges in the cold-sensitive cultivars were more obvious than those in the strong cold resistance ones; the MAD contents in leaves were in a rise-fall sequence while the MAD contents in the cold-sensitive cultivars were much higher than those in the cold-resistant ones; under low temperature stress, the SOD and POD activities in leaves of cold-sensitive cultivars dropped greater than those in the strong cold-resistant ones; the contents of proline, soluble sugar and soluble liquid protein in leaves increased more seemingly in the cold-resistant cultivars than in the cold-sensitive ones. The contents of soluble sugar and soluble liquid protein in leaves were in a rise-fall trend as the temperature dropped and time elapsed. There was a dramatic decline in the chlorophyll contents and water ratios in leaves under the low temperature stress, more seemingly in the weak cold resistance cultivars than in the stronger ones. Conclusions: It was obvious that there was a close relation between the cold resistance and the cell membrane permeability, MDA contents, SOD and POD activities and the contents of proline, soluble sugar and soluble protein in different cassava cultivars. And those physiological characters could be used as indexes of cold resistance.
\end{abstract}

Keywords: Cassava, Low temperature stress, Cold resistance, Physiological characters

\section{Introduction}

Guangxi is the main cassava growing area in China, with an annual planting area of $350,000-400,000 \mathrm{hm}^{2}$, accounting for $60 \%$ of the total of the country. Cassava is a good starch crop with important biomass energy significance. To date, the biomass energy industry with cassava as the main raw materials has become the new yet important industry in China. A tropical crop as it is, cassava is sensitive to low temperature and cold damage. Guangxi has the monsoon climate with frequent low temperature; frost and cold damage occurring in autumn and winter, which is a strong impact on the growth of cassava. To study the hardy physiological mechanism and select the hardy cultivars are urgent and important for the development of cassava industry. Studies have been done on the cold resistance of crops both at home and abroad. Sun Qun (2006) pointed out in his research that the harm caused to crops by low temperature could be divided into two types---cold damage and frost damage, respectively, based on the temperature and damage. Zeng Guang'an (2006) reported that there was a correlation between low temperature and cell membrane demage. According to the study by Chen Yajun (1996), under low temperature stress, the proline content in cold-sensitive clover cultivars increase faster than those in the cold-resistant cultivars. Results from the studies by Jiang Fuying (2002), Chen Chanyou (2005), Wang Fenghua (2006) and Peng Yanhua (1992) have shown that the cold resistance of crops is correlated with the soluble protein contents. Studies by Shi Fuchen (2007) and Zobayed (2005) have revealed that the activities of SOD and POD in crop leaves and roots drop under low temperature stress, while the report by Oshua-Otieno Ogweno (2009) indicated that SOD and POD activities in tomato leaves maintains under low temperature. Ou Yi (2006) and Ren Xuqin (2006) reported that the cold resistance of sweet persimmon and chili was correlated with the 
increase in the proline content. However, it seems that there are not so many researches on the hardy physiological mechanism of cassava revealed at home and abroad. SC124 and Fuxuan 01, two hardy cassava cultivars and Nanzhi 199 and SC205, another two cold-sensitive cassava cultivars were studied through low temperature stress in order to explore the hardy physiological characters of different cassava cultivars and provide theoretical and technical basis for the breeding and the cultivation of hardy cassava cultivars and physiological control for cold-resistance cultivation.

\section{Materials and Methods}

\subsection{Cultivars}

The study was conducted in the teaching and scientific research base and the key lab for plant cultivation and agronomics of Guangxi University. Cultivars tested included two cold-resistant cassava cultivars (SC124 and Fuxuan 01) and two cold-sensitive cassava cultivars (Nanzhi 199 and SC205).

\subsection{Treatment}

Cassava was cultured in sands and then treated by low temperature stress when the young plants were with 7-8 fully opened leaves. The plants were put in the GXZ intelligent lighting incubator (intensity of illumination set during daytime: $7500 \mathrm{LX}$, nighttime: $0 \mathrm{LX}, 12 \mathrm{~h}$ each for daytime and nighttime) at $5{ }^{\circ} \mathrm{C}, 10{ }^{\circ} \mathrm{C}, 15^{\circ} \mathrm{C}$ and $25^{\circ} \mathrm{C}$ for $1,3,5$ and 7 days with the control group cultured at $25^{\circ} \mathrm{C}$ for 3 repeated times. The functional leaves (the $4^{\text {th }}$ leave from the top) of the treated young plants were collected for various physiological tests. Due to various degrees of wilt of the plants after low temperature stress, all parameters were normalized against the dry weights of the leaves.

\subsection{Physiological Parameter Determination}

\subsubsection{Cell Membrane Permeability}

$0.3 \mathrm{~g}$ leaves were cut and put in the weighing bottle with $10 \mathrm{ml}$ of deionized water. The samples were vacuumed for $20 \mathrm{~min}$ and shaken for $2 \mathrm{~h}$. The conductivity (Rt1) of the leaching solution was measured after $2 \mathrm{~min}$ rest. The solution was boiled for $15 \mathrm{~min}$ at $100{ }^{\circ} \mathrm{C}$ water bath and cooled down to 25 . The conductivity of (Rt2) was measured. The electrical conductivity of the deionized water (Rt0) was measured as the negative control.

Formula: relative membrane permeability $(\%)=($ Rt1 - Rt0 $) /($ Rt2- Rt0 $) \times 100$

\subsubsection{SOD Activity}

\section{(1) Enzyme extraction}

$1000 \mathrm{~g}$ fresh leaves were grounded on ice with $10 \mathrm{ml} 0.05 \mathrm{M}$ pH7.8 phosphate buffer. Mixture was then centrifuged at $10000 \mathrm{rmp}\left(0 \sim 4{ }^{\circ} \mathrm{C}\right)$ for 10 15 min, and the supernatant was collected.

(2) Enzyme activity measurement

Reagents were added in the following orders: $1.5 \mathrm{ml} 0.05 \mathrm{~mol} / \mathrm{L}$ phosphate buffer, $0.3 \mathrm{ml} 130 \mathrm{mmol} / \mathrm{L} \mathrm{Met}$ solution; $0.3 \mathrm{ml} 750 \mu \mathrm{mol} / \mathrm{L}$ nitroblue tetrazolium (NBT) solution; $0.3 \mathrm{ml} 100 \mu \mathrm{mol} / \mathrm{L}$ EDTA $-\mathrm{Na}_{2}$ solution; $0.3 \mathrm{ml} 20 \mu \mathrm{mol} / \mathrm{L}$ riboflavin; $0.1 \mathrm{ml}$ enzyme liquid; $0.5 \mathrm{ml}$ distilled water to total volume $3.3 \mathrm{ml}$

Another 4-6 test tubes were used as the control group, with buffer instead of enzyme solution. 2 control tubes were put in dark, while the other control tubes were exposed in $4000 \mathrm{Lx}$ daylight for reaction of $20 \mathrm{~min}$ (all tubes were exposed to the same illumination; exposure time was adjusted according to the temperature). OD560 were measured in light-exposed tubes, with tubes incubated in dark as blank control.

Formula:

Given that the SOD activity unit was presented by the $50 \%$ of the inhibited NBT photo-reduction as the unit of enzyme activity, the SOD activity was calculated using the following formula:

$$
\begin{aligned}
& \text { Total SODactivity }=\left(\mathrm{OD}_{\mathrm{CK}}-\mathrm{OD}_{\mathrm{E}}\right) \times \mathrm{V} /\left(\mathrm{OD}_{\mathrm{CK}} \times 0.5 \times \mathrm{W} \times \mathrm{V}_{\mathrm{t}}\right) \\
& \text { SOD specific activity }=\mathrm{SOD} \text { Total activity } / \text { protein content }
\end{aligned}
$$

Where: SOD total activity was presented by the wet weight of each gram of enzyme unit; specific activity presented by enzyme unit/mg; ODck representing the absorbance of the irradiated control tubes; $\mathrm{OD}_{\mathrm{E}}$ representing the absorbance of the sample tubes; V for the total vol. of the samples (ml); Vt for the dosage of samples used for calculation (ml); W for the wet weight of the samples $(\mathrm{g})$; unit of protein content: $\mathrm{mg}$ protein/g wet weight 


\subsubsection{POD Activity}

(1) Enzyme extraction: same as that for SOD enzyme liquid

(2) Enzyme activity measurement:

$3 \mathrm{ml}$ substrate solution $\left(100 \mathrm{ml} 0.1 \mathrm{M} \mathrm{pH} 6.0\right.$ phosphate buffer with $0.5 \mathrm{ml}$ guaiacol and $1 \mathrm{ml} 30 \% \mathrm{H}_{2} \mathrm{O}_{2}$, well mixed) was mixed with $0.05 \mathrm{ml}$ of enzyme extracted solution, quickly shaken well then put into a cuvette. The substrate solution without enzyme was used as the blank group. OD470 was recorded once every $15 \mathrm{~s}$ for 3 min. if time allowed for scanning, directly recorded the starting/ending intervals of the major straight slope and the corresponding absorbance.

\subsection{Calculation}

Peroxidase activity $\left(\triangle \mathrm{OD} 470 \cdot \mathrm{g}^{-1} \cdot \mathrm{FW} \cdot \mathrm{min}^{-1}\right)=$

\subsubsection{MDA Content}

MDA content was determined according to the Phytophysiology Experimental Method by Guangxi University (2005), using the same extraction method as that for SOD enzyme. Specifically as the following: the mixture of $2 \mathrm{ml}$ supernatant ( $2 \mathrm{ml}$ distilled water for the control group) with $2 \mathrm{ml} 0.6 \%$ TBA was boiled in water bath for 15 $\min$, then centrifuged at $4000 \mathrm{r} / \mathrm{min}$ for $10 \mathrm{~min}$ after cooled down. ABS values at $532 \mathrm{~nm}, 600 \mathrm{~nm}$ and $450 \mathrm{~nm}$ were measured, and the MDA contents were calculated as the following:

$$
\text { Formula: } \mathrm{C}_{\mathrm{MDA}}=6.45\left(\mathrm{~A}_{532}-\mathrm{A}_{600}\right)-0.56 \mathrm{~A}_{450}(\mathrm{mmol} / \mathrm{L})
$$

MDA concentration in the extracted liquid was calculated the as per the following formula

MDA concentration in the extracted liquid $(\mu \mathrm{mol} / \mathrm{ml})=$

$$
\mathrm{C}_{\mathrm{mda}} \times \text { reaction liquid vol.(ml)/1000 }
$$

MDA content was calculated the as the following formula:

$$
\text { Dosage of extracted liquid during measurement }(\mathrm{ml})
$$

MDA concentration of extracted liquid $(\mu \mathrm{mol} / \mathrm{ml}) \times$ gross extracted liquid $(\mathrm{ml}) \times 1000$ MDA content $\left(\mathrm{nmol} \cdot \mathrm{g}^{-1} \mathrm{FW}\right)=$

\subsubsection{Proline Content}

$$
\text { Wet weight of plant tissue (g) }
$$

The sulfosalicylic acid method as described in the Crop Physiologic Methodology by Zhang Xianzheng (1992) was applied. $0.5 \mathrm{~g}$ Fresh cassava leaves without the midrib was cut into pieces and $5 \mathrm{ml} 3 \%$ of sulfosalicylic acid was added. Mixture was incubated in boiling water bath for $10 \mathrm{~min} .2 \mathrm{ml}$ extracted solution was transferred into a new tube, followed by $2 \mathrm{ml}$ water, $2 \mathrm{ml}$ glacial acetic acid and $4 \mathrm{ml}$ ninhydrin, mixed well and heated in boiling water for development for $60 \mathrm{~min}$. After the mixture was cooled down, $4 \mathrm{ml}$ toluene was added and mixed. Supernatant was transferred and absorbance at $520 \mathrm{~nm}$ was measured.

Formula:

$$
\text { Proline content }\left(\mu \mathrm{g} \cdot \mathrm{g}^{-1}\right)=\frac{\mathrm{C} \times \mathrm{V} / \mathrm{a}}{\mathrm{W}}
$$

C stands for the $\mu \mathrm{g}$ of the proline from the index line; V for the gross vol. of the extracted liquid (ml); a for the vol. of the measured liquid ( $\mathrm{ml})$; $\mathrm{W}$ for the wet weight of the plant tissue (g).

\subsubsection{Soluble Protein Content}

The Coomassie brilliant blue G-250 staining method as described in the Technique for Plant Physiologic and Biochemical Experiment by Li Hesheng (1999) was applied: $0.5 \mathrm{~g}$ Fresh cassava leaves without the midrib was cut into pieces, homogenated with $5 \mathrm{ml}$ distilled water, and then centrifuged at $4000 \mathrm{r} / \mathrm{min}$ for $10 \mathrm{~min} .1 .0 \mathrm{ml}$ supernatant was mixed with $5 \mathrm{ml}$ Coomassie brilliant blue G-250 liquid and absorbance at $595 \mathrm{~nm}$ was measured after $2 \mathrm{~min}$.

Formula:

$$
\text { Protein content of the sample }(\mathrm{mg} / \mathrm{g})=\mathrm{C} \times \mathrm{V}_{\mathrm{T}} /\left(\mathrm{V}_{\mathrm{S}} \times \mathrm{W}_{\mathrm{F}} \times 1000\right)
$$

Where: $\mathrm{C}$ for the standard curve, $\mathrm{V}_{\mathrm{T}}$ total vol. of the extracted liquid, $\mathrm{V}_{\mathrm{S}}$ for the added specimen during measurement, $\mathrm{W}_{\mathrm{F}}$ for wet weight of the sample 


\subsubsection{Soluble Sugar}

The Anthrone colorimetric method as described in the Crop Physiologic Methodology by Zhang Xianzheng (1992) was applied: 0.5-1 g Fresh cassava leaves without the midrib was cut into pieces, added into $25 \mathrm{ml}$ distilled water and boiled in water bath for 20 min then cooled down and filtered. Washed the residues with distilled water several times, and added to the filtered solution to final volume of $100 \mathrm{ml} .1 .0 \mathrm{ml}$ solution was mixed with $1.5 \mathrm{ml}$ water and $6.5 \mathrm{ml}$ of anthrone agent, and absorbance at $620 \mathrm{~nm}$ was measured.

Formula:

$$
\text { Soluble sugar in leaves }(\%)=\mathrm{C} \times 100 \times 100 / 0.5 \times 10^{6} \times \mathrm{W}=2 \times 0.01 \times \mathrm{C} / \mathrm{W}
$$

Where: $\mathrm{C}$ for standard curve, $\mathrm{W}$ for the wet weight of the sample.

\subsubsection{Chlorophyll Content}

The acetone-ethanol mixture process as described in the Crop Physiologic Methodology by Zhang Xianzheng (1992) was applied: $0.1 \mathrm{~g}$ Fresh cassava leaves without the midrib was cut into slides, put into a capped bottle, incubated with $10 \mathrm{ml}$ acetone ethanol mixed extracting solution, and shaken in dark at room temperature till the leaves completely turned white. Absorbance of the clear liquid at $663 \mathrm{~nm}$ and at $645 \mathrm{~nm}$ was measured, and the chlorophyll content was calculated as per the following formula:

$$
\begin{aligned}
& \text { Total chlorophyll content }\left(\mathrm{mg} \cdot \mathrm{g}^{-1}\right)=\left(8.02 \mathrm{~A}_{663}+20.21 \mathrm{~A}_{645}\right) \times \mathrm{V} / 1000 \mathrm{~W} \text {, namely } \\
& \text { Total chlorophyll content }\left(\mathrm{mg} \cdot \mathrm{g}^{-1}\right)=\left(8.02 \mathrm{~A}_{663}+20.21 \mathrm{~A}_{645}\right) \times 0.01 / \mathrm{W}
\end{aligned}
$$

Where: $\mathrm{A}_{663}$ and $\mathrm{A}_{645}$-respectively for the measured absorbance at $663 \mathrm{~nm}$ and $645 \mathrm{~nm}$ of the chlorophyll; $\mathrm{V}$ - vol. of the extracted liquid (ml); W-weight of materil (g).

\subsubsection{Water Ratio of Leaves}

Dry aluminum container was weighed and recorded as M0. Fresh cassava leaves in the aluminum container was weighed and recorded as M1. Leaves in the aluminum container was baked till there was no more weight loss, weighed and recorded as M2. Calculated the water ratio in leaves as per the following formula:

$$
\text { Water ratio in leaves }(\%)=\frac{\mathrm{M} 1-\mathrm{M} 2}{\mathrm{M} 2-\mathrm{M} 0} \times 100
$$

\subsection{Data Process and Analysis}

Data were processed and interpreted using Excel while statistics and analysis using statistical software "DPS3.10".

\section{Results and Analysis}

\subsection{Changes in Cell Membrane Permeability in Different Cassava Cultivars under Low Temperature Stress}

The primary indicator reflecting cassava cell membrane permeability is the relative conductivity of the leaves. Intracellular substances effusion can cause changes in cell conductibility. Relative conductance of different cassava cultivars under low temperature stress were presented in (Figure 1), where it showed that the relative conductivity of the leaves of the 4 tested cassava cultivars increased significantly under low temperature stress as the temperature dropped and time elapsed, with greater increases in the leaves of the cold-sensitive cultivars than the cold-resistant ones. Therefore, the cell membrane permeability increased after suffering cold damage and such increase was more obvious in the cold-sensitive cultivars.

\subsection{Changes in Cassava Leave SOD Activities from Different Cultivars under Low Temperature Stress}

The SOD activity of different cassava cultivars under low temperature stress were presented in (Figure 2). It showed that there was a significant difference in SOD changes in the leaves of different cassava cultivars. Under low temperature stress, the SOD activities of the cold-sensitive cultivars (Nanzhi 199, SC205) increased at the very beginning and then dropped as time went by and temperature decreased, while those in the cold-resistant cultivars (SC124, FuXuan01) kept steady increasing.

\subsection{Changes in POD Activities of Different Cassava Cultivars under Low Temperature Stress}

The POD activity of different cassava cultivars under low temperature stress were presented in (Figure 3). It showed that at room temperature $\left(25^{\circ} \mathrm{C}\right)$, the POD activities of the cold sensitive cultivars (Nanzhi199, SC205) were higher than those in the cold-resistant cultivars (SC124, FuXuan01) while the POD activities of the cold-resistant cultivars were higher at lower temperature $\left(5^{\circ} \mathrm{C}, 10^{\circ} \mathrm{C}\right.$ and $\left.15^{\circ} \mathrm{C}\right)$. 


\subsection{Changes in MDA Contents of Leaves of Different Cassava Cultivars under Low Temperature Stress}

The MDA content of different cassava cultivars under low temperature stress were presented in (Figure 4). It showed no obvious difference in the MDA changes in all the 4 tested cultivars at $15{ }^{\circ} \mathrm{C}$ and $25{ }^{\circ} \mathrm{C}$ as time elapsed. However, the MDA contents in SC124 and FuXuan 01 were higher than those in Nanzhi199 and SC205, indicating that the MDA contents in the cold-resistant cultivars were higher than those in the cold-sensitive ones under mild stress. While the temperature dropped to $10^{\circ} \mathrm{C}$ and as time elapsed, the changes in MDA contents in Nanzhi199 and SC205 showed a rise-fall trend while those in SC124 and FuXuan 01 in a declining trend. The MDA contents of all the 4 cassava cultivars dropped at $5{ }^{\circ} \mathrm{C}$.

\subsection{Changes in Proline Contents of Leaves of Different Cassava Cultivars under Low Temperature Stress}

There was a significant difference in proline contents in leaves from different cassava cultivars under low temperature stress. It is showed in (Figure 5) that as the temperature dropped and time elapsed at $5{ }^{\circ} \mathrm{C}, 10{ }^{\circ} \mathrm{C}$, $15{ }^{\circ} \mathrm{C}$ and $25^{\circ} \mathrm{C}$, the proline contents increased, more seemingly in the cold-sensitive cultivars (Nanzhi199 and SC205) than the cold-resistant ones (SC124 and FuXuan01). The proline contents increased by $184.97 \%$ in SC205, 116.87\% in Nanzhi199, 49.45\% in SC124 and 48.48\% in FuXuan 01 respectively at Day 7 at $15{ }^{\circ} \mathrm{C}$ compared with those at Day 1; the proline contents increased by $195.95 \%$ in Nanzhi199, $87.35 \%$ in SC205, $47.31 \%$ in SC124 and $23.27 \%$ in FuXuan 01 respectively at Day 7 at $10{ }^{\circ} \mathrm{C}$ compared with those at Day 1; the proline contents increased by respectively $311.66 \%, 153.95 \%, 71.97 \%$ and $71.63 \%$ at Day 7 at $5{ }^{\circ} \mathrm{C}$ compared with those at Day 1, which indicated that cold resistance had a close correlation with the changes in proline contents.

\subsection{Changes in Soluble Protein Contents of Leaves of Different Cassava Cultivars under Low Temperature Stress}

Soluble protein content of different cassava cultivars under low temperature stress were presented in (Figure 6). There was no significant difference in the soluble protein content in all 4 cultivars at $25{ }^{\circ} \mathrm{C}$, though those in SC124 and FuXuan01 were higher than those in Nanzhi199 and SC205; there was a significant increase in the soluble protein content in all 4 cultivars at $15{ }^{\circ} \mathrm{C}$ compared with those at $25{ }^{\circ} \mathrm{C}$. The soluble protein content in Nanzhi199 and SC205 dropped after reaching the peak at Day 1 while those in SC124 and FuXuan01 reached their maximum levels at Day 5 and Day 3 respectively. The soluble protein content in all the 4 cultivars showed a declining trend at both $10^{\circ} \mathrm{C}$ and $5{ }^{\circ} \mathrm{C}$ as the stress time elapsed.

\subsection{Changes in Soluble Sugar Contents of Leaves of Different Cassava Cultivars under Low Temperature Stress}

The soluble protein content of different cassava cultivars under low temperature stress were presented in (Figure 7). It showed that the soluble sugar contents in all 4 cultivars slowly increased at $25{ }^{\circ} \mathrm{C}$ along with stress, and the soluble contents in SC124 and FuXuan 01 were higher than those in Nanzhi199 and SC205. There was an obvious increase in SC205, SC124 and FuXuan01 at $15{ }^{\circ} \mathrm{C}$ compared with those at $25{ }^{\circ} \mathrm{C}$ while the increase in Nanzhi199 was not so obvious. At $10^{\circ} \mathrm{C}$, the soluble sugar content in Nanzhi199 increased the most while those in SC205, SC124 and FuXuan 01 began to drop. At $5{ }^{\circ} \mathrm{C}$, the soluble sugar contents in Nanzhi199 and SC205 increased along the stress while those in $\mathrm{SC} 124$ and FuXuan01 dropped.

\subsection{Changes in Water Ratios of Leaves of Different Cassava Cultivars under Low Temperature Stress}

The soluble protein content of different cassava cultivars under low temperature stress were presented in (Figure.8). It showed no obvious changes in the water ratios in all the cultivars at $15{ }^{\circ} \mathrm{C}$ and $25{ }^{\circ} \mathrm{C}$ while at $5{ }^{\circ} \mathrm{C}$ and $10{ }^{\circ} \mathrm{C}$, the water ratios gradually dropped along with the stress with an obvious drop in the cold sensitive cultivars than those in the cold-resistant one. The water ratios in leaves at Day 7 at $5{ }^{\circ} \mathrm{C}$ dropped by $31.22 \%$, 30.79\%, 15.57\% and 13.97\% in Nanzhi199, SC205, SC 124 and FuXuan01 compared with those at Day 1.

\subsection{Evaluation of Cold Resistance of Different Cassava Cultivars}

The methods as described by Liu Yong (2000) and Duan Xiaocui (2005) was applied: fuzzing mathematics membership degree formula was used for quantity conversion among the values of the 8 measured indicators---relative conductivity, SOD activity, POD activity, MDA content, proline content, soluble protein content, soluble sugar content and water ratio in leaves. Given the weight coefficient was 0.2 for relative conductivity, 0.15 respectively for SOD activity and POD activity and 0.1 respectively for MDA content, proline content, soluble protein content, soluble sugar content and water ratio in leaves. The overall evaluation of the cold resistance of all the tested cultivars after calculation was shown in (Table1). It showed that the indicators in SC124 and FuXuan01 were quite close and significantly higher than those in SC205 and Nanzhi 199, which conformed the cold resistance phenotype we observed. Therefore, such method is proved to be applicable for evaluating cold resistance of cassava. 


\section{Discussion}

\subsection{Relation between Membrane Permeability and Cold Resistance}

The adaptation to low temperature of plants mainly lies in the cell membrane, especially the plasmalemma and thylakoid membrane. Cell membrane protects the plants from the outside environment. There is a correlation between normal physiological function and the activity and phase state of membrane-bound enzyme. Normal phase state of membrane is in liquid crystal state. While temperature drops below the critical point, membrane fluidity also reduces while previous random arranged lipid chains become ordered arranged, resulting in changes in membrane shape and thickness and possible holes or cracks which may lead to the increase in membrane permeability. The increased efflux of the intracellular content (such as inorganic ions, amino acid and sugar) causes increased conductivity (Huang Haishan, 2007) The conductivity increases significantly as the low temperature stress enhances, while the increase in the cold-resistant crops is less obvious than that in the cold-sensitive cultivars (Shi Xuehui, 1997). This experiment shows that the relative conductivity of leaves from all the 4 tested cassava cultivars increased along with the declination of the temperature and time length of stress, more significantly in the cold-sensitive cultivars (Nanzhi199 and SC205) than in the cold-resistant ones (SC124 and FuXuan01). This is because the cold sensitive cultivars suffered more serious cold damage than the cold resistant ones. Hence, the change in membrane permeability can be used as an indicator to monitor the cold damage to cassava.

\subsection{Relationship between Protective Enzyme and Cold Resistance}

SOD is one of the enzymes of the protective enzyme system of plants. Its main function is to erase $\mathrm{O}_{2}{ }^{-}$and form $\mathrm{H}_{2} \mathrm{O}_{2}$. Therefore SOD activities increase within a certain range of low temperature to maintain the balance of active oxygen. Yet along with the increase of low temperature stress, the active oxygen and free radical seemingly also increase causing the decline in SOD activities. Results of this experiment: along with the drop in temperature and increase in time of stress, the SOD enzyme activities of the cassava leaves showed a rise-fall trend, which agreed to the results of studies in scallion by Zhang Zhonghua (2006) and studies in alfalfa by Deng Xueke (2005).

\subsection{Relationship between MDA and Cold Resistance}

Under low temperature stress, the increase in free radicals and decrease in erased ones causes the increase in the accumulation of free radicals which exceeds the damages. These free radicals can cause the stop in chain, decompounding and destroy in the unsaturated fatty acid within the oxidation film structure, namely, the process of membrane lipid peroxidation leading to the end product---MDA (Sun Changzhu,1998). Such MDA combined with membrane protein will destroy to the membrane structure causing the entocyte leakage and cold damage to plants (Zhang Xueming, 1990; Wang Xiyan, 2009). Results of this experiment: along with the drop in temperature and increase in time of stress, the MDA contents in leaves of young cassava showed a rise-fall trend, more seemingly increase in the nonhardy cultivars (Nanzhi199 and SC205) than in the hardy ones (SC124 and FuXuan01). Hence, MDA content can be used as an indicator to evaluate the cold resistance in cassava.

\subsection{Relationship between Proline Content and Cold Resistance}

With regard to the relation between proline content and cold resistance, there are different conclusions from different researches. Some hold that proline content has a positive correlation with cold resistance and can be used as an indicator to evaluate the cold resistance in plants: research by Ou Yi (2006) showed that the increase in proline contents in hardy sweet persimmon cultivars was greater than that in the nonhardy ones under low temperature stress. Study by Binbin Lu (2005) also showed that the proline content in paddy roots doubled at $20^{\circ} \mathrm{C}$. Ren Xuqin (2006) shared the same opinion from her research in chili. However, there are also researches that come to a different conclusion---proline content has a negative correlation with cold resistance. According to Chen Yajun (1996), the accumulation of proline was greater with earlier peak in nonhardy colver cultivars than the hardy ones under low temperature stress. Results of this experiment showed that the proline accumulation kept increasing along with the drop of temperature and time length in cassava leaves, the increase of proline contents in hardy cultivars at the lowest set temperature was less than that in the nonhardy ones. The increase in proline contents of Nanzhi199 and SC205 was higher than that in SC124 and FuXuan01 at whichever of the 4 set temperatures, indicating the negative correlation between proline content and cold resistance in cassava.

\subsection{Relationship between Soluble Protein and Cold Resistance}

Soluble protein is an important protective substance in plant with strong hydrophilic colloid property which can enhance the water retention of cells. Therefore, the increase in soluble protein can enhance the cold resistance under low temperature stress. This conclusion has been confirmed in the studies of asparagus beans, eggplants, 
common waaterrthacinth and grapes (Chen Chanyou, 2005; Wang Fenghua, 2006; Peng Yanhua, 1992; Attila Hegedus, 2008). Result of this experiment showed that no obvious differences in the soluble protein contents between the hardy and nonhardy cultivars at room temperature $\left(25^{\circ} \mathrm{C}\right)$ while the soluble protein contents in SC124 and FuXuan 01 were seemingly higher than those in Nanzhi199 and $\mathrm{SC} 205$ at $10^{\circ} \mathrm{C}$; at $5{ }^{\circ} \mathrm{C}$, the soluble protein content in FuXuan 01 was much higher than those in Nanzhi199 and SC205 while the increase in SC124 was not obvious, indicating that the cold resistance of hardy cultivars can be enhanced by increasing soluble protein while the temperature is around $10{ }^{\circ} \mathrm{C}$; while the temperature drops to below $5^{\circ} \mathrm{C}$, it is still possible to strengthen the cold resistance by increasing soluble protein content for some hardy cultivars such as FuXuan01, however this does not work for $\mathrm{SC} 124$. This shows that the soluble protein content at $10{ }^{\circ} \mathrm{C}$ can be used as an indicator for general cold damage evaluation.

\subsection{Relationship between Soluble Sugar and Cold Resistance}

Under low temperature stress, the macromolecular substances of the cells of plants hydrolyze which causes the increase in soluble sugar, lowers the ice point of tissues or cells and produces more protective substances and energy through saccharometabolism (Alejandro G., 1997; Oshua-Otieno Ogweno, 2009) as well as increases the cell hydrature, enhances water retention, avoids dehydration and damages of bioplasm at low temperature and consequently protects the bioplasm membranes (Sun Qun, 2006; Yang Dong, 2007; Wang Xinghu, 2005; Christine H. Foyer, 2002; Oscar G., 2010). The results of this experiment showed that the soluble sugar contents in all 4 tested cultivars at $10^{\circ} \mathrm{C}$ and $15{ }^{\circ} \mathrm{C}$ were higher than those at room temperature $\left(25^{\circ} \mathrm{C}\right)$. However, the contents in soluble sugar at $5{ }^{\circ} \mathrm{C}$ were lower than those at room temperature $\left(25^{\circ} \mathrm{C}\right)$, indicating that it is possible to enhance the cold resistance in cassava by increasing the soluble sugar contents in cassava cells at $10^{\circ} \mathrm{C}$ and $15^{\circ} \mathrm{C}$, this method does not work while temperature drops to below $5{ }^{\circ} \mathrm{C}$.

\subsection{Relationship between Water Ratio in Cassava Leaves and Cold Resistance}

Results of this experiment showed that under low temperature stress, the water ratio in leaves decreased seemingly, and more obvious in nonhardy cultivars than in hardy ones. Hence, changes in water ratio in leaves under low temperature stress can be used as an indicator for cold resistance evaluation in cassava.

\section{Conclusions}

Under low temperature stress, the cell membrane permeability of cassava leaves increase---more seemingly in the nonhardy cultivars; MDA contents in cassava leaves increase, more seemingly in nonhardy cultivars than in hardy ones; SOD and POD activities decrease, more seemingly in nonhardy cultivars; significant increase in proline, soluble sugar and soluble protein contents, more seemingly in hardy cultivars. The soluble sugar and soluble protein contents show a rise-fall trend as the temperature drops and time length increases. Under low temperature stress, the chlorophyll contents land water ratio dramatically declines, more seemingly in nonhardy cultivars, indicating that cell membrane permeability, MDA content, SOD and POD activities, proline content, soluble sugar and soluble protein contents have a close relation with cassava cold resistance. Such physiologic indexes can be used in cassava cold resistance evaluation.

\section{Reference}

Alejandro, G. Marangoni, Patricia, M., Duplessis, \& Rickey, Y. Yada. (1997). Kinetic model for carbon partitioning in Solanum tuberosum tubers stored at $2{ }^{\circ} \mathrm{C}$ and the mechanism for low temperature stress-induced accumulation of reducing sugars. Biophysical Chemistry, 65, 211-220.

Attila, hegedus, Tibor, Janda, Gabor, V., Horvath, Denes, Dudits. (2008). Accumulation of overproduced ferritin in the Chloroplast provides protection against photo inhibition induced by low temperature in tobacco plants. Journal of Plant Physiology, 165, 164-165.

Binbin, Lu, Yongze, Yuan, Chufu, Zhang, Jiquan, Ou, Wei, Zhou, \& Qinghua, Lin. (2005). Modulation of keyenzymes involved inammonium assimilation and Carbon metabolism by low temperature in rice (Oryzasativa L.) roots. Plant Science, 169, 295-300.

Cen, Ya-jun, Cui, Guowen, \& Fu, Xiangqian. (1996). The Effects of Low Temperature Stress on The proline content of alfalfa. Grassland of Chin, 6, 46-47.

Chen, Chanyou, Wang, Huidong, \& Ding, Yi. (2005). Changes of Soluble Protein Content and Activities of Cell Protective Enzymes under Chilling Stress in Asparagus Bean Seedlings. Acta Hortic Sin, 32(5), 911-913.

Christin, eH. Foyer, Helne, Vanack, Leonardo, D. Gomae, \& Jeremy, Harbinson. (2002). Regulation of photosynthesis and antioxidant metabolism in maize Leaves at optimal and chilling temperatures review. Plant Physiol. Biochem, 40, 659-668. 
Deng, Xueke, Qiao, Dairong, \& Li, Liang. (2005). The Effect of Chilling Stress on Physiological Characters of Medicago sativa. J Sichuan Univ, 42(1), 190-194

Duan, Xiaocui, Ni, Zhiyun, Lu, Bingshe, Bai, Zhiying, \& Li, Xianming. (2005). Study on cold resistance of four Pistachio varieties by freezing treatment. Journal of Agricultural University of Hebei, 28(4), 48-50.

Huang, Haisan. (2007). Studies on the Physiological Characteristics for Cold Resistance of Grape. Paper for Doctor in Gansu Agric. Univ., 10-89.

Jiang, Fuying, Li, Yan, \& Weng, Baiqi. (2002). Review on Physiology of Chilling Stress and Chilling Resistance of Plants. Fujian J Agric. Sci., 17(3), 190-195.

Li, Hesheng. (1999). The Experimental Techniques of Plant Physiology. High Educat Press, Bejing, 123-212.

Liu, Yong, Chen, Yan, Zhang, Zhiyi, \& Li, Xinguo. (2000). Effects of fertilizer treatments on seedling growth and cold resistance of triploid Populus tomentosa. Journal of Beijing Forestry University, 1, 38-44.

Oscar, G., Bodeln, Mara, Blanch, Mara, T., Sanchez-Ballesta, Mara, I. Escribano, \& Carmen Mer. (2010). The effects of high $\mathrm{CO}_{2}$ levels on anthocyanin composition, antioxidant activity and soluble sugar content of strawberries stored at low non-freezing temperature. Food Chemistry, 122, 673-678.

Oshua-Otieno, Ogweno, Xing-Shun, Song, Wen-Hai, Hu, Kai, Shi, Yan-Hong, Zhou, \& Jing-Quan, Yu. (2009). Detached leaves of tomato differ in their photosynthetic physiological response to moderate high and low temperature stress. Scientia Horticulturae, 123, 17-22.

Ou, Yi, Xie, Yonghong, \& WANG, Jin. Effect of temperature and PEG stress on the accumulation of free proline in persimmon leaves. Southwest Chin J Agric Sci, 19(3), 470-472.

Peng, Yanhua, Liu, Chengyun, Lu, Dayan, \& Xie, Wan-cheng. (1992). Response of Water Hyacinth Leaves to Low Temperature Emperature Stress-Increase in Abscisic Acid And Soluble Protein Concentrations. $J$ Wuhan Botan Research, 10(2), 123-127.

Ren, Xuqin, Zhang, Linqing, \& Sun, Min. (2006). Study on Physiology Response of Pepper Leaf to Low Temperature. J Anhui Agric Sci, 34(24), 6439-6440.

Shi, Fuchen. (2007). Bao Fang. Effects of salinity and temperature stress on ecophysiological characteristics of exotic cordgrass, Spartina alterniflora. Acta Ecologica Sinica, 27(7), 2733-2741.

Shi, Xuehui, Liu, Kunyu, Yang, Guoshun, Lv, Changping, Wang, Shuying, \& Luo, Chuanhui. (1997). Influences of Low Temperature Stress on The Permeability of Plasma Membrane, The Contents of MDA And V C of Citrusexcised Leaves. J Hunan Agric Univ, 1997, 23(1), 36-40.

Zobayed, F. Afreen, \& T. Kozai. (2005). Temperatur stress can alter the photosynthetic efficiency and secondary metabolite concentrations in St. John's wort. Plant Physiology and Biochemistry, 43, 977-984.

Sun, Changzu, \& Liu, Jiaqi. (1998). Effects of Chilling Stress on O - 2、MDA, Membrane Permeability, Leaf Water Potential, Protective Enzyme of Leaves in Populus Cathayana. J Neimenggu Forestry College, 20(3), $32-36$.

Sun, Qun, \& Hu, Jingjiang. (2006). Research Techniques in Plant Physiology. Xibei Agric And Forest Univ Press, Shanxi, 68.

Wang Fenghua, Gao, Wei-na, \& Lin, Deqing. Effects of $\mathrm{Ca} \sim(2+)$ on Protein Content and Specific Protein of Eggplant Seedling under Chilling Stress. J Henan Agric Sci, 6, 86-88.

Wang, Xinghu. (2005). Effect of Low temperature Stress on Physiological \& Biochemical properties And seedling growth of Muskmelon. Paper for Doctor in Gansu Agric Univ, 6, 25-56.

Wang, Xiyan, Zhang, Yulong, \& Zhang, Hengming. (2009). Influence of Silicon on Activities of Protective Enzymes and MDA Content in Cucumber under Salt Stress Soil. Acta Agric Boreali-Occidentalis Sin, 18(1) 221-224, 233.

Yang, Dong, Zhang, Hong, Chen, Li-ping, \& Ma, Dan-wei. Effect of Temperature Stress on Propanedial and Soluble Sugar Contents in Ten Compositae Weeds. J Sichuan Normal Univ., 30(3), 391-394.

Zeng, Guang-an, \& Jiang, De-an. (2006). Plant Physiology. Chin Agric Press, Bejing, 329-330.

Zhang, Xianzheng. (1992). Resaerch Methods of Crop Physiology. Chin Agric Press, Bejing, 23-96.

Zhang, Xueming, \& Guo, Shaochuan. (1990). The Change of Content of MDA And SOD Activeties of Hybrid Rice under Low temperature Stress. Hunan Agric Sci, 3, 13-38. 
Zhang, Zhonghua, Yang, Jianping, Chen, Shengdong, \& Wang, Qinghua. (2006). Effect of Low Temperature Stress on Protective Enzyme Activity and Membrane Permeability in Chinese Chives. Acta Agric Boreali-Occidentalis Sin, 15(2), 124-127.

Table 1. The comprehensive evaluation of cold hardiness in cassava cultivars

\begin{tabular}{|c|c|c|c|c|c|c|c|c|c|c|}
\hline cultivars & X1 & X2 & X3 & X4 & X5 & X6 & X7 & X8 & $\begin{array}{l}\text { The comprehensive } \\
\text { evaluation }\end{array}$ & position \\
\hline Nanzhi199 & 0.233 & 0.093 & 0.257 & 0.050 & 0.741 & 0.394 & 0.575 & 0.454 & 0.321 & 4 \\
SC205 & 0.116 & 0.879 & 0.585 & 0.541 & 0.404 & 0.092 & 0.337 & 0.025 & 0.383 & 3 \\
SC124 & 0.817 & 0.991 & 0.728 & 0.570 & 0.434 & 0.750 & 0.337 & 0.579 & 0.688 & 1 \\
Fuxuan01 & 0.520 & 0.701 & 0.609 & 0.694 & 0.584 & 0.845 & 0.746 & 1.000 & 0.687 & 2 \\
proportion & 0.2 & 0.15 & 0.15 & 0.1 & 0.1 & 0.1 & 0.1 & 0.1 & & \\
\hline
\end{tabular}

Note: Table.1 X1: relative conductivity; X2: SOD activity; X3: POD activity; X4: MDA content; X5: praline content; X6: soluble protein content; X7: soluble sugar content; X8: leaf water content

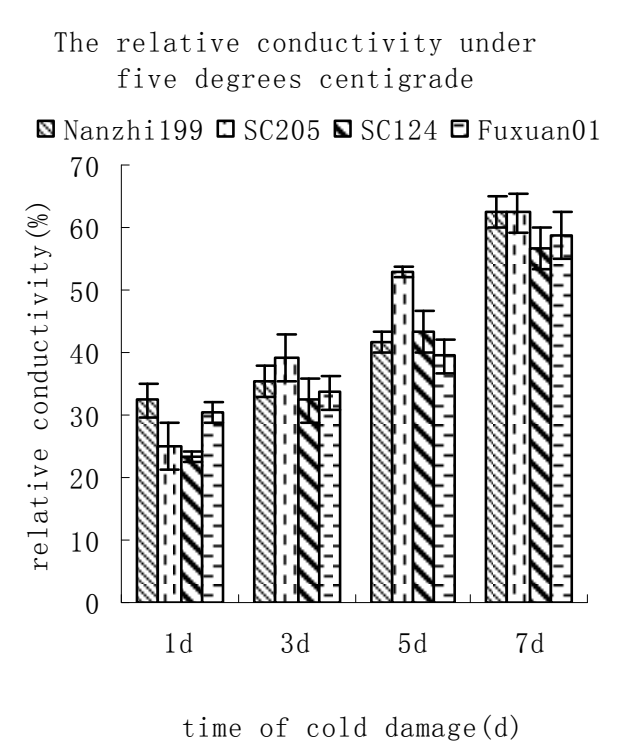

The relative conductivity under

fifteen degrees centigrade

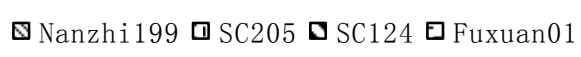

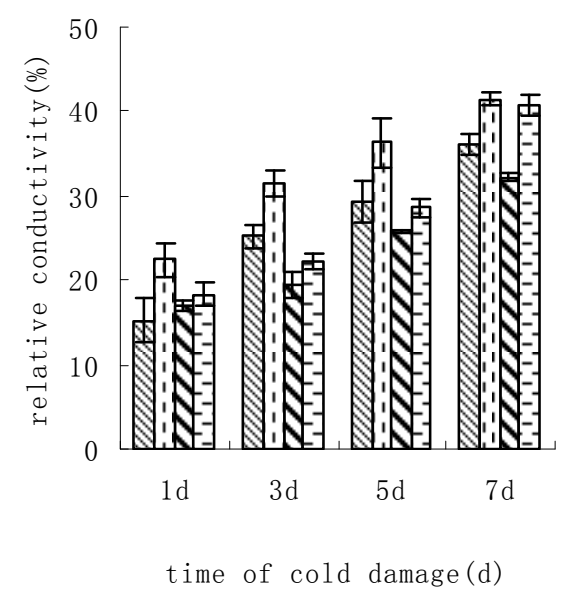

The relative conductivity under

ten degrees centigrade

$\boldsymbol{\otimes}$ Nanzhi199 $\boldsymbol{\square}$ SC205 $\mathbf{S}$ SC124 घFuxuan01

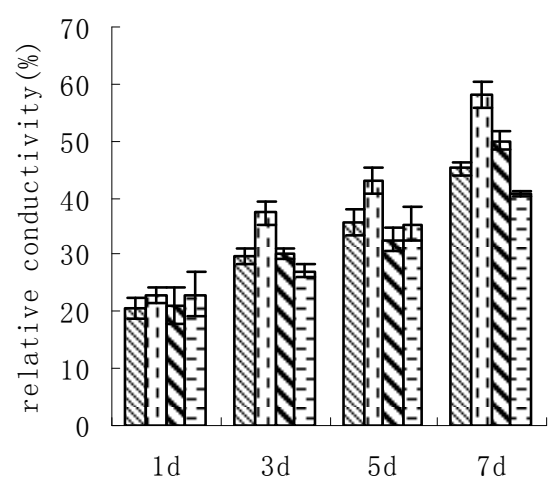

time of cold damage(d)

The relative conductivity under

twenty five degrees centigrade

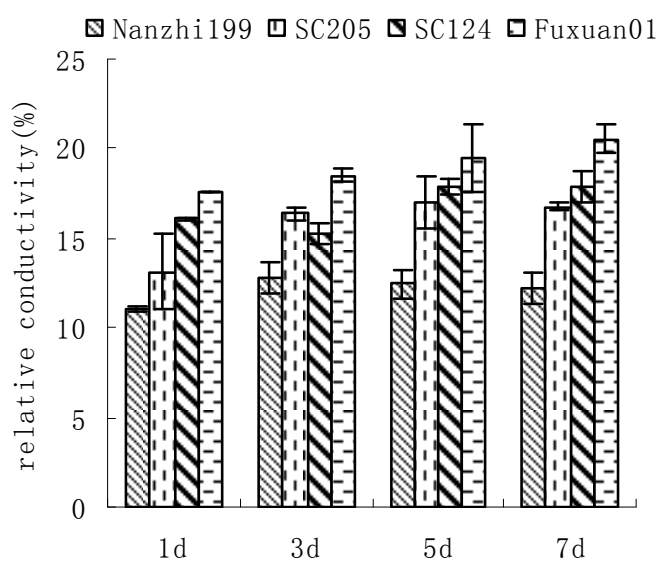

time of cold damage(d)

Figure 1. Change of relative conductivity in different cassava varieties under low temperature stress 

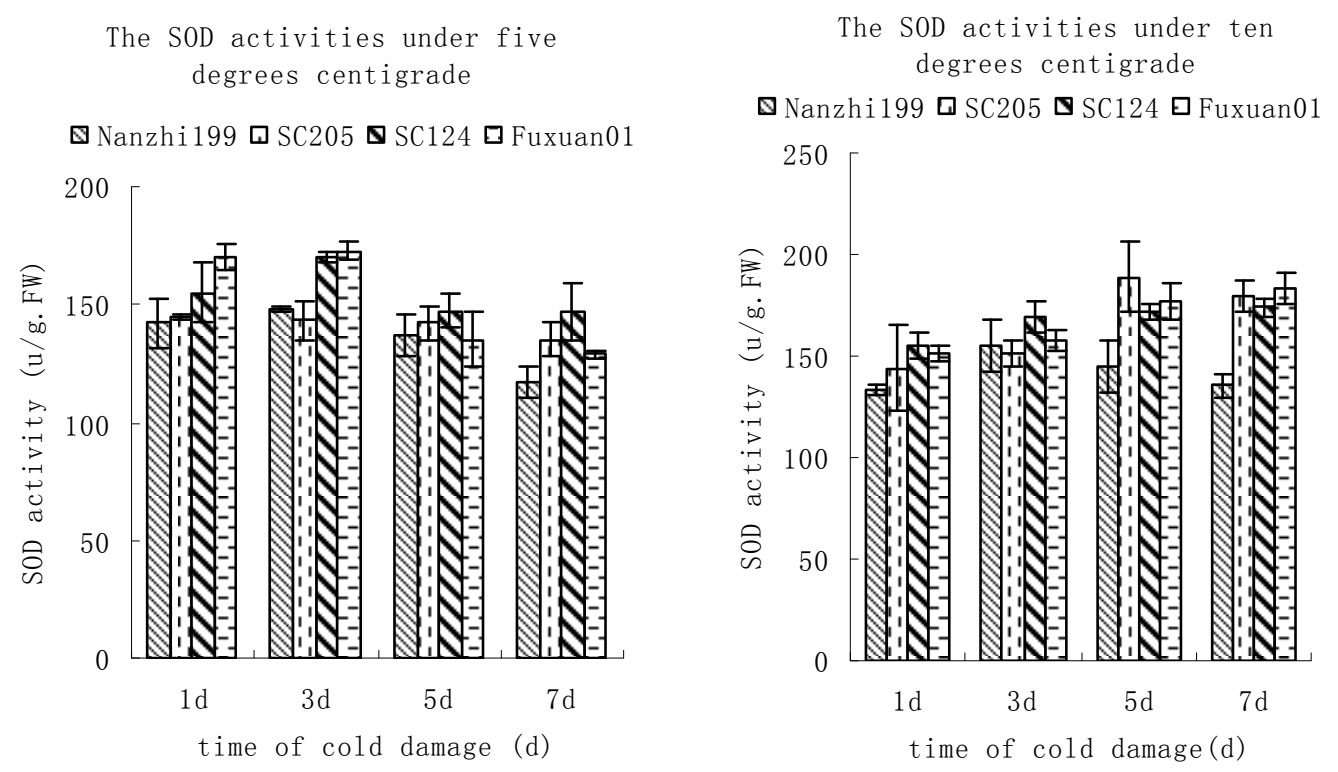

The SOD activities under fifteen degrees centigrade

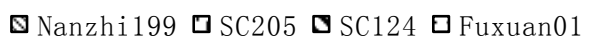

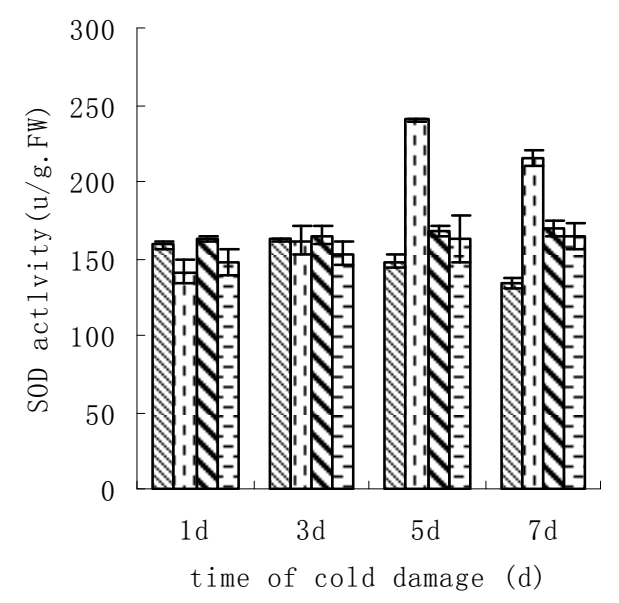

The SOD activities under twenty

five degrees centigrade

\& Nanzhi199 SC205 DSC124 घFuxuan01

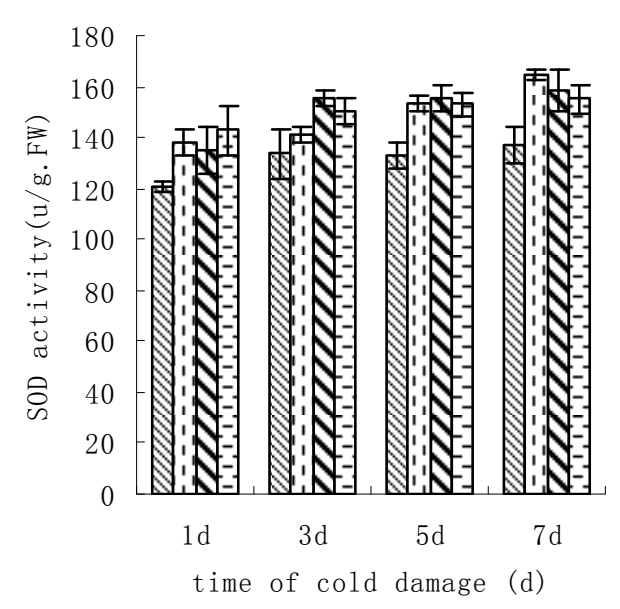

Figure 2. Change of SOD activity in different cassava varieties under low temperature stress 
The POD activities under five degrees centigrade

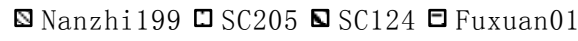

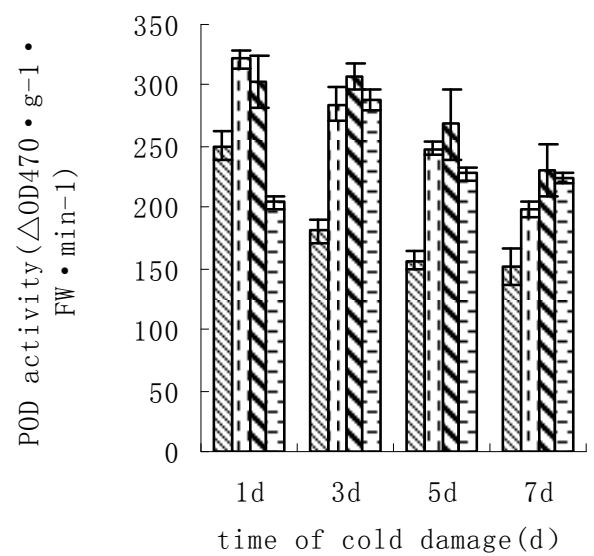

The POD activities under fifteen degrees centigrade

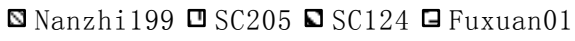

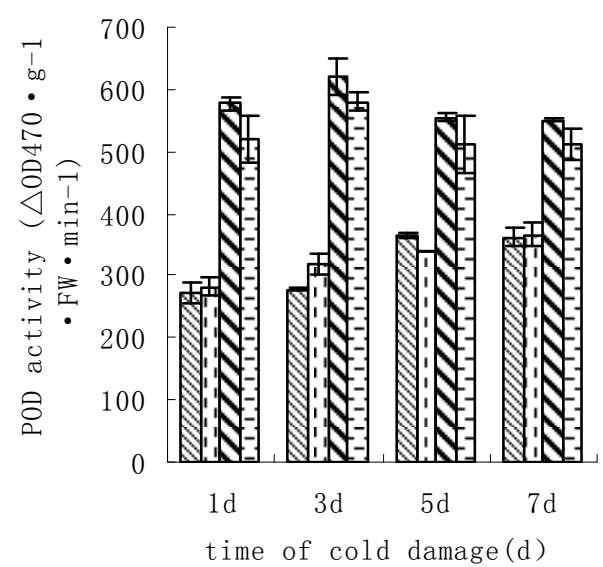

The POD activities under ten

degrees centigrade

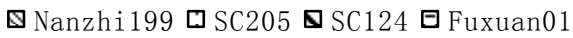

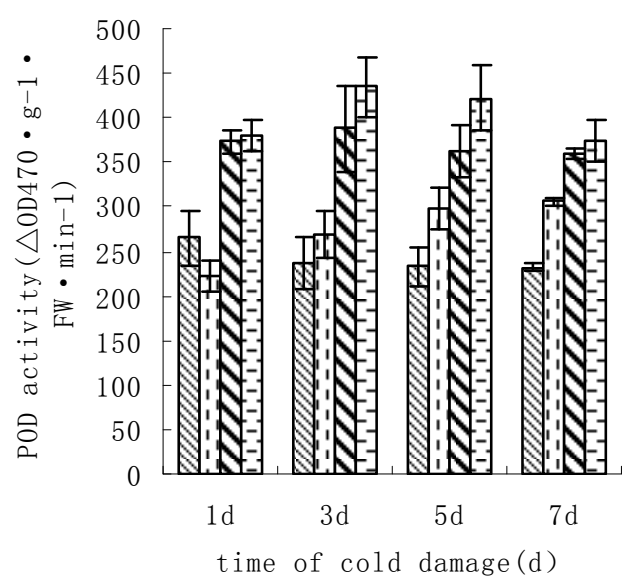

The POD activities under twenty

five degrees centigrade

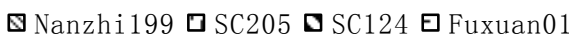

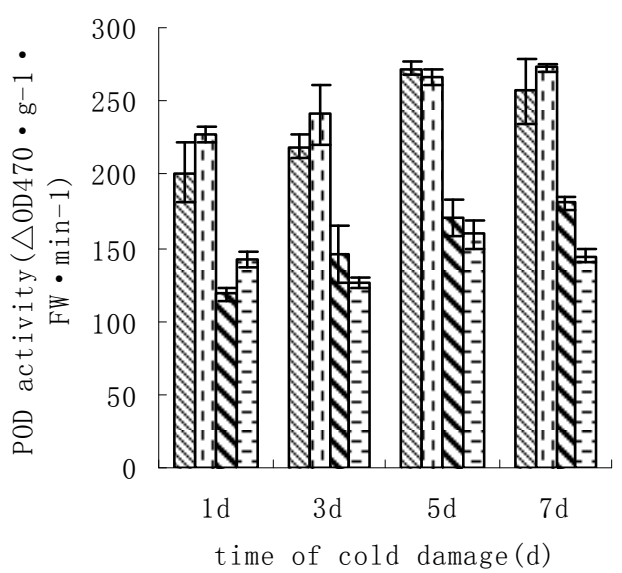

Figure 3. Change of POD activity in different cassava varieties under low temperature stress 


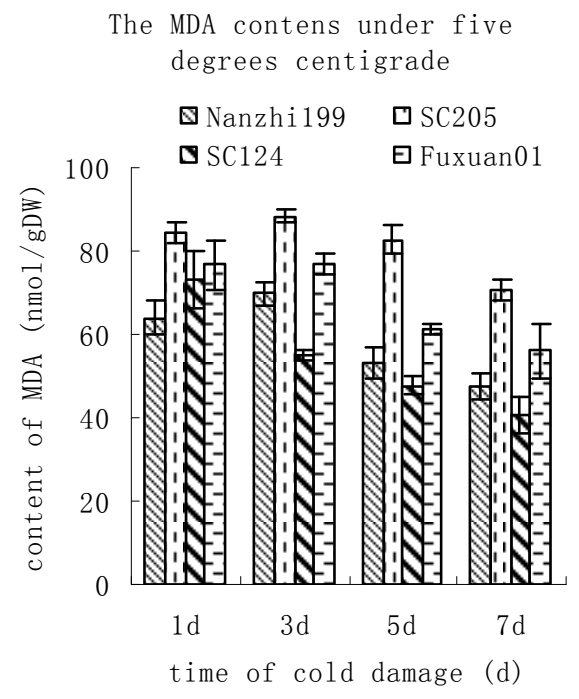

The MDA contens under fifteen degrees centigrade

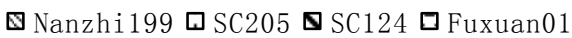

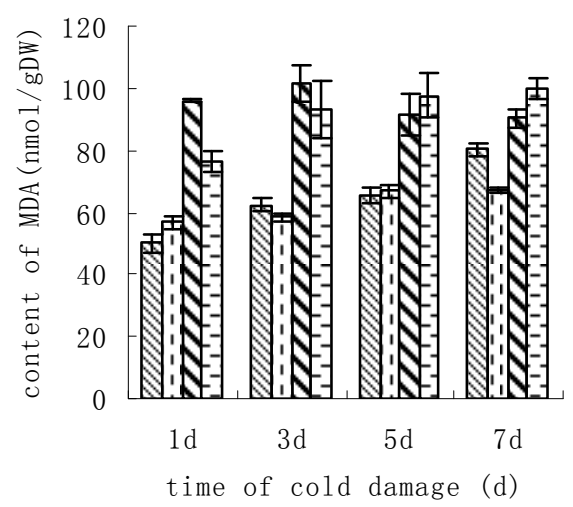

The MDA contens under ten degrees centigrade

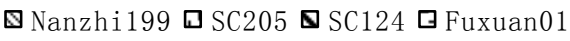

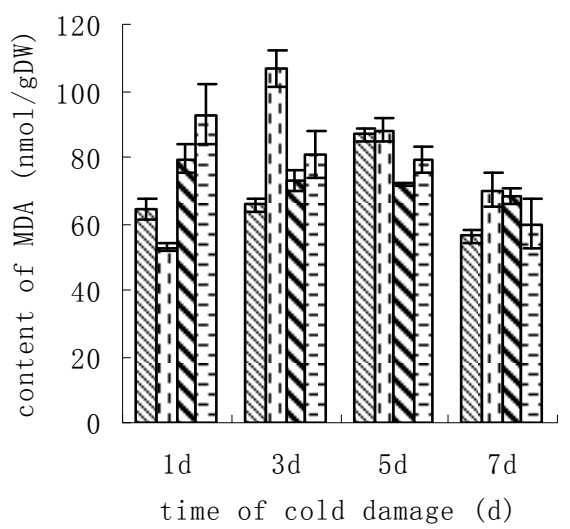

The MDA contens under twenty five degrees centigrade

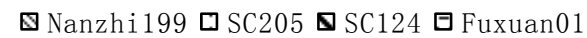

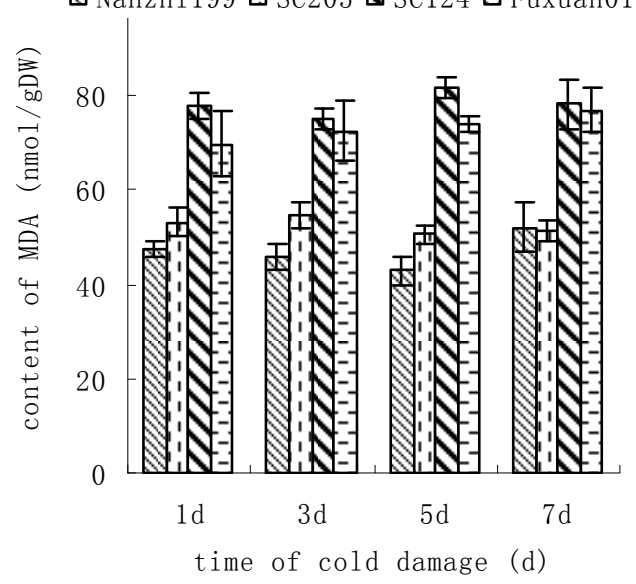

Figure 4. Change of MDA content in different cassava varieties under low temperature stress 
The proline contents under five degrees centigrade

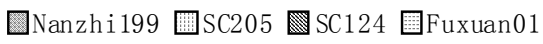

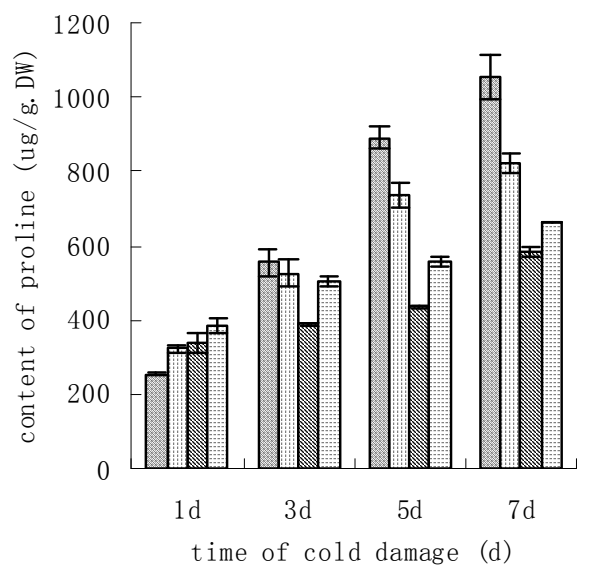

The proline contents under fifteen degrees centigrade

\Nanzhi199 SC205 $\mathbf{S C} 124 \boldsymbol{0}$ Fuxuan01

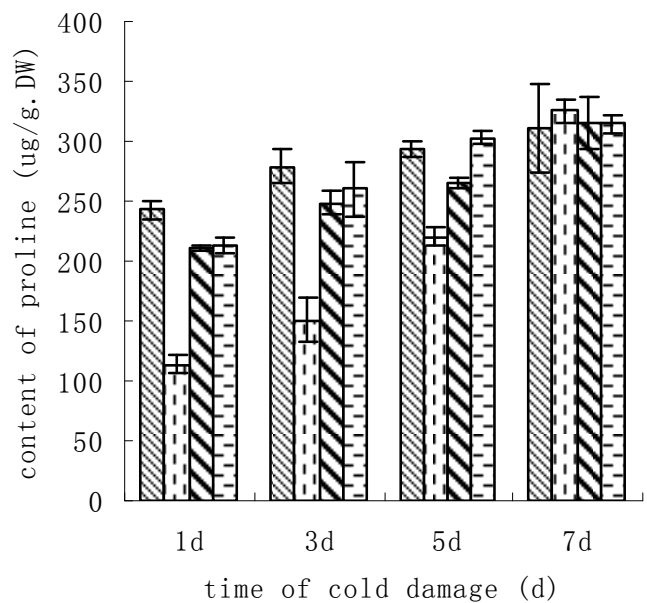

The proline contents under ten

degrees centigrade

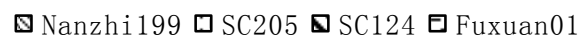

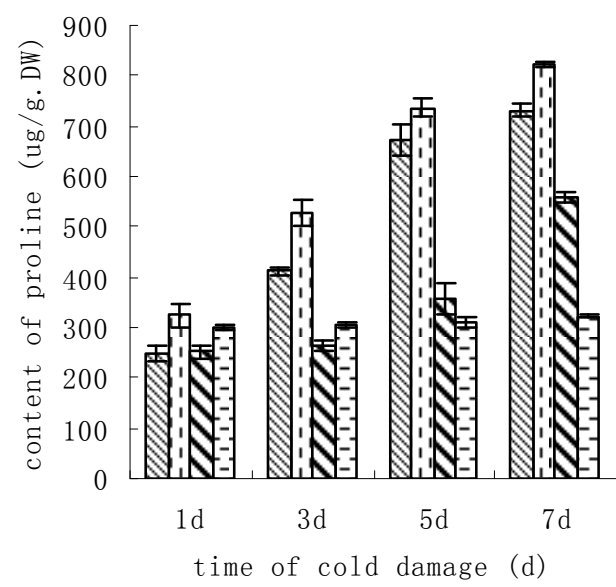

The proline contents under twenty five degrees centigrade

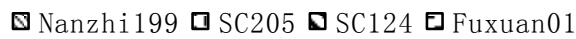

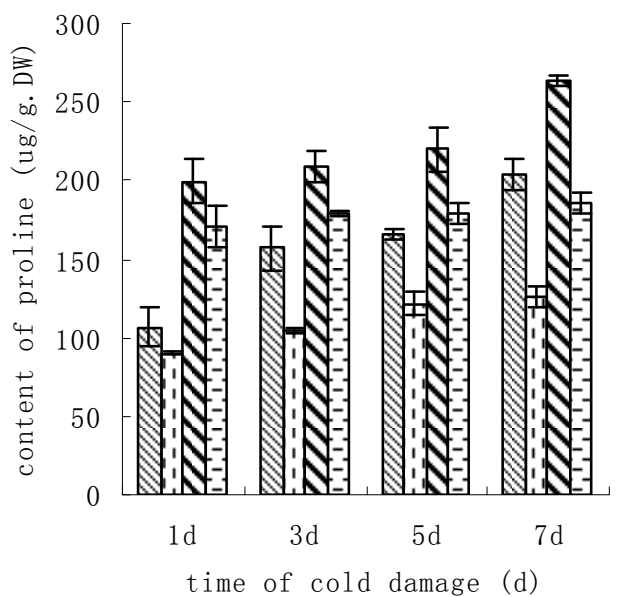

Figure 5. Change of proline content in different cassava varieties under low temperature stress 


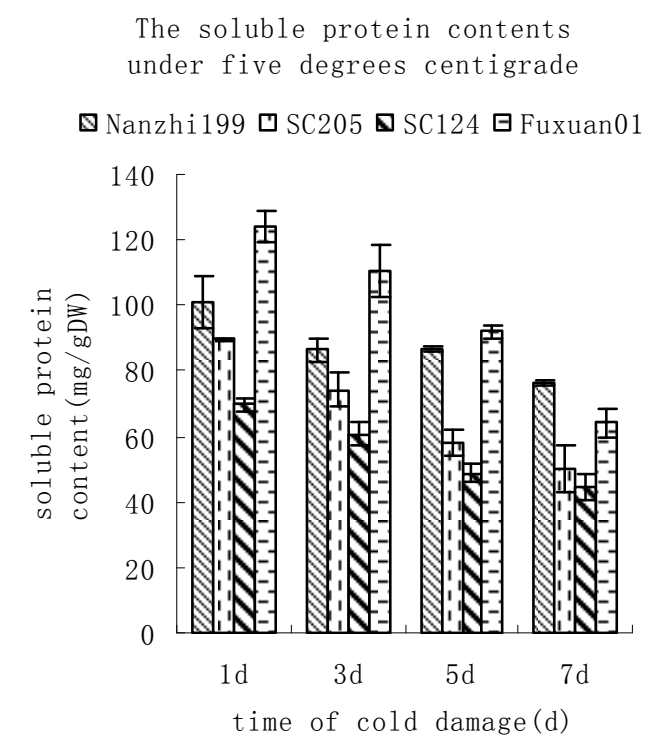

The soluble protein contents under fifteen degrees centigrade

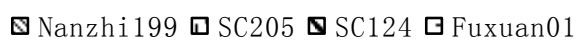

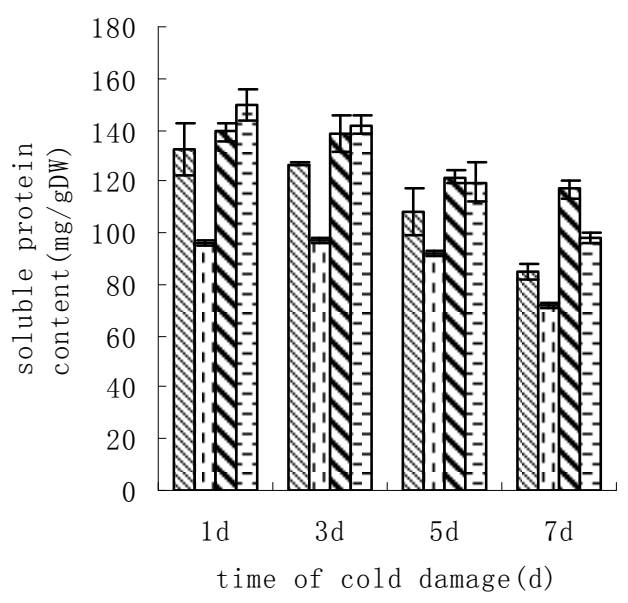

The soluble protein contents under ten degrees centigrade

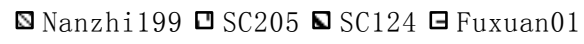

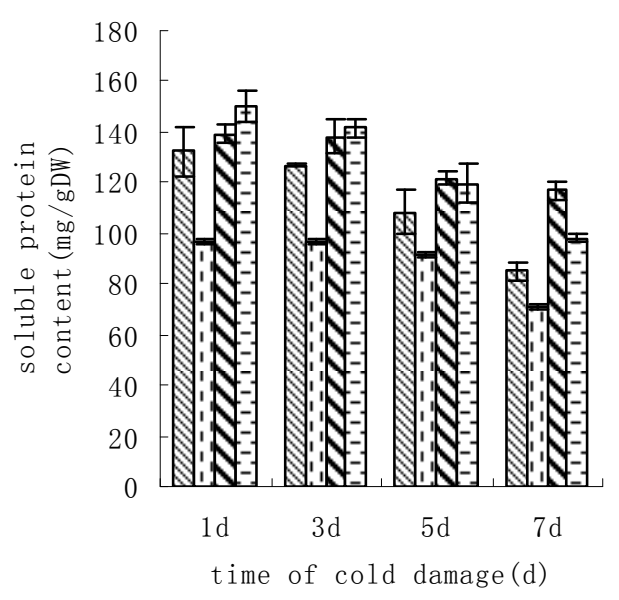

The soluble protein contents under twenty five degrees centigrade

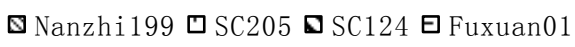

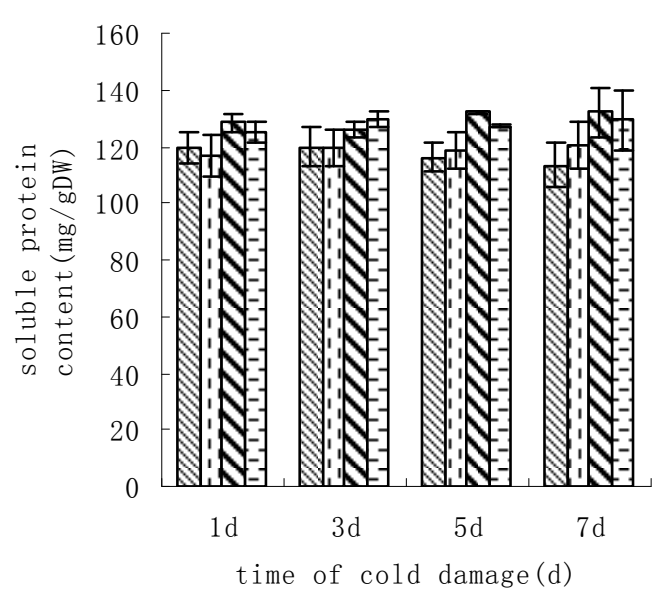

Figure 6. Change of soluble protein content in different cassava varieties under low temperature stress 
The soluble sugar contents under fifteen degrees centigrade

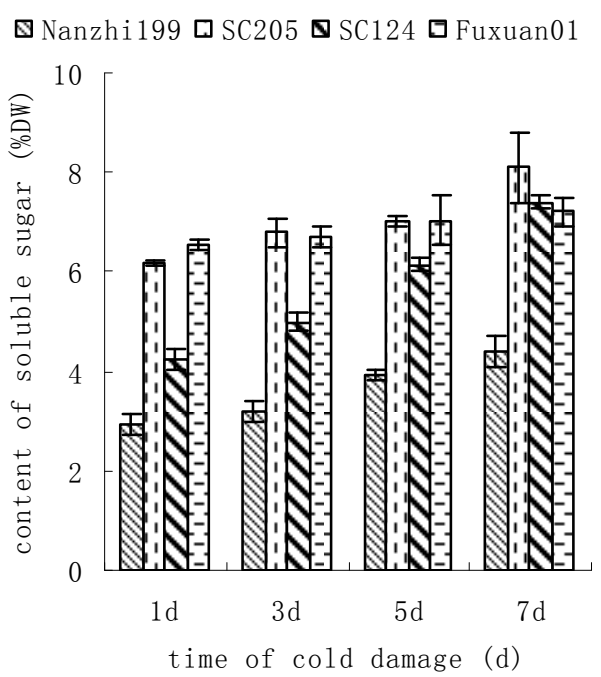

The soluble sugar contents under fifteen degrees centigrade

\& Nanzhi199 SC205 D SC124 日Fuxuan01

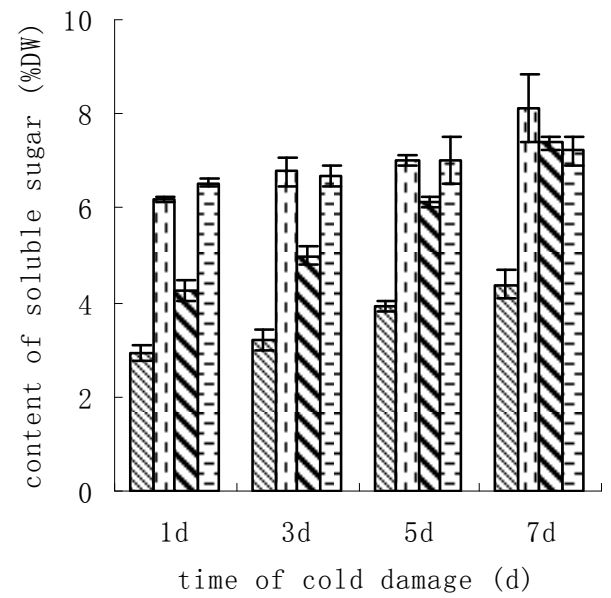

The soluble sugar contents under ten degrees centigrade

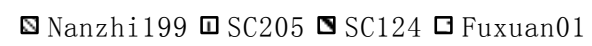

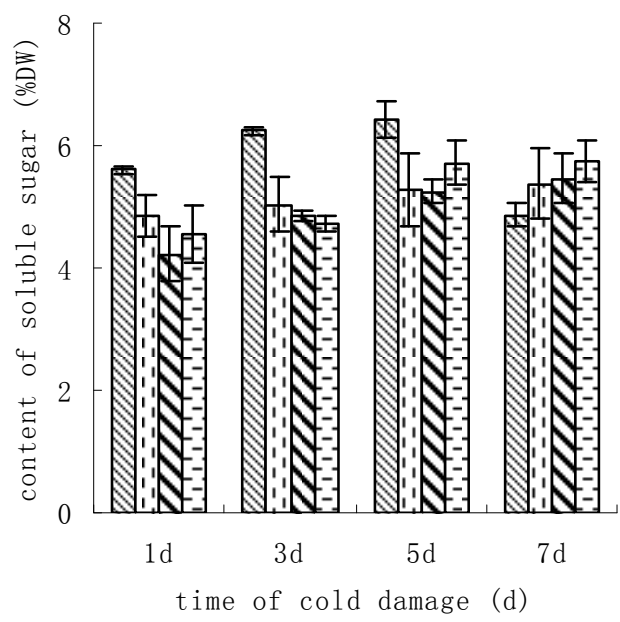

The soluble sugar contents under twenty five degrees centigrade

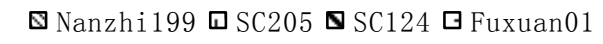

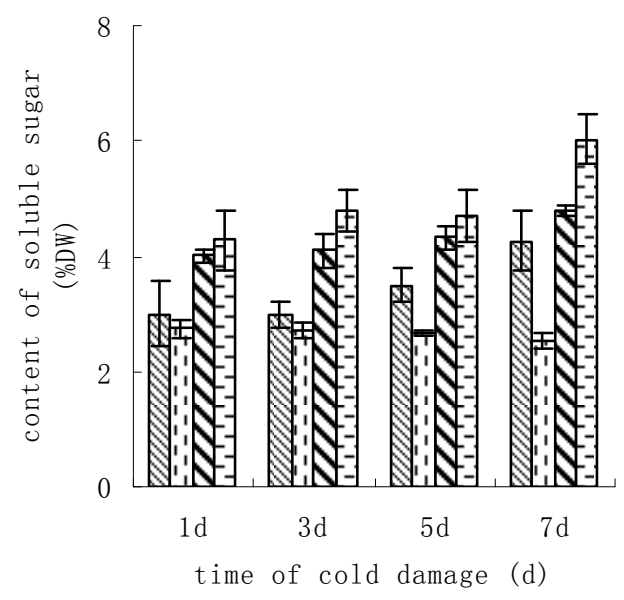

Figure 7. Change of soluble sugar content in different cassava varieties under low temperature stress 

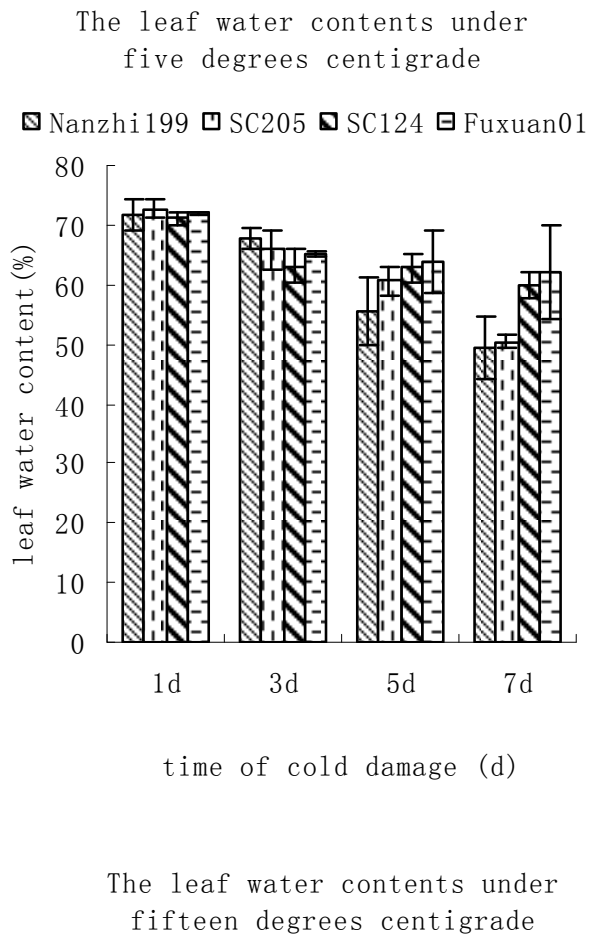

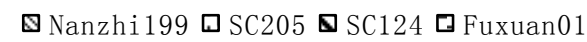

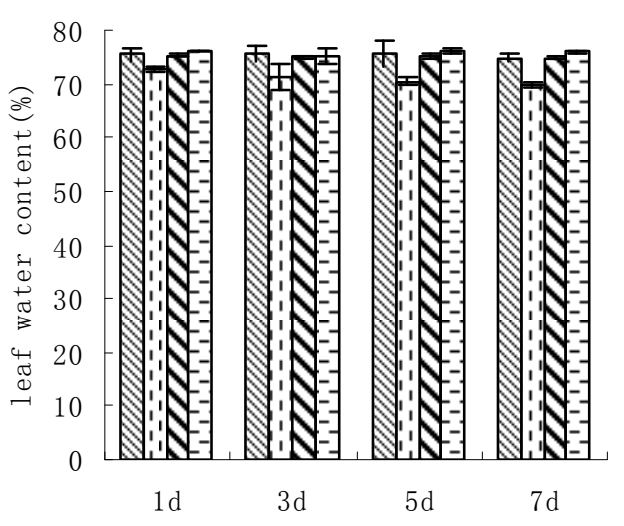

time of cold damage (d)
The leaf water contents under ten degrees centigrade

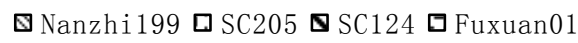

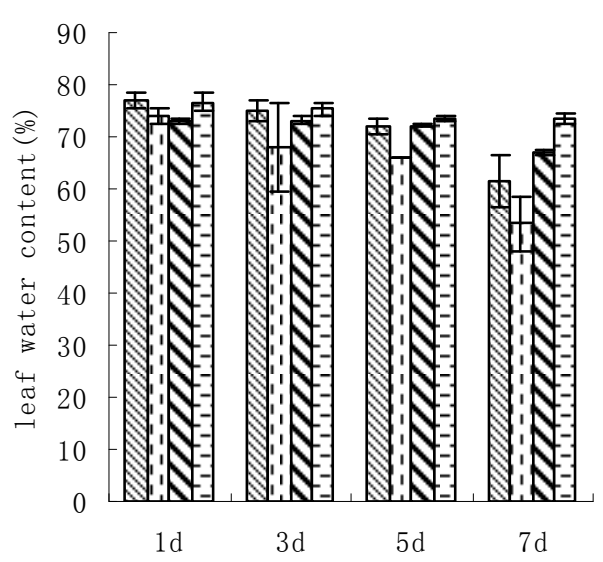

time of cold damage (d)

The leaf water contents under twenty five degrees centigrade

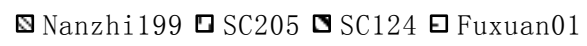

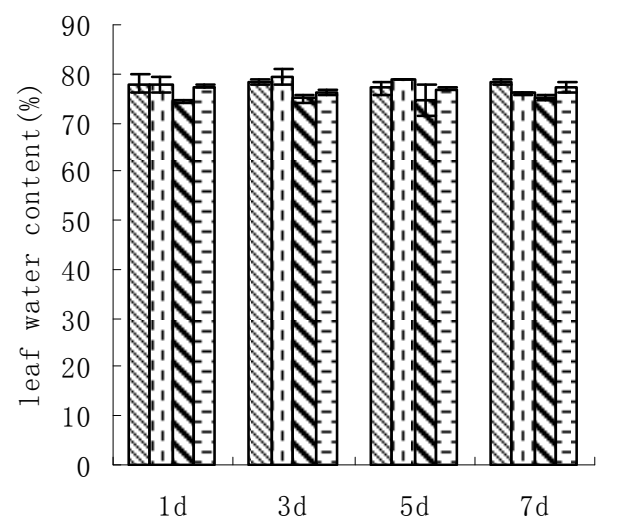

time of cold damage (d)

Figure 8. Change of leaf water content in different cassava varieties under low temperature stress 